\title{
RECLAIMED ASPHALT PAVEMENT (RAP) BASED ON A GEOSPATIAL INFORMATION SYSTEM (GIS)
}

\author{
Hossein HARIRI ASLI' ${ }^{1 *}$, Mahyar ARABANI ${ }^{1}$, Yaser GOLPOUR ${ }^{1}$
}

\begin{abstract}
A Geospatial Information System (GIS) is a system designed to capture, store, manipulate, analyze, manage, and present spatial or geospatial data. Reclaimed Asphalt Pavement (RAP) based on the GIS is one of the indirect and efficient methods in identifying areas. In this work, an analytical computational process combined with a spatial analysis was used to identify pavement zones for a city. The zoning results were categorized in four classes, including very high, high, medium risk, and low risk zones. The high and very high risk zones have been considered as a whole. The work circumstances include the Mean Profile Depth (MPD) data as a function of the number of wheel passes and the temperature; ten (10) specimens were selected from a set of 23 specimens. The results showed a good correlation between the parameters, including the number of wheels passing, the temperature, and the MPD.
\end{abstract}

\section{Address}

1 Dept. of Civil Engineering, Faculty of Engineering, University of Guilan, Rasht, Iran

* Corresponding author: hossein_hariri@msc.guilan.ac.ir

\section{Key words}

- Pavement;

- Geospatial Information Systems (GIS);

- Regression;

- Analytical computational process.

\section{INTRODUCTION}

Recycling asphalt pavement is an environmental user friendly method with the aim of the optimized use of natural resources. Looking at its benefits and cost, it also makes the processing and production practices less expensive for new asphalt and energy expenditures. A pavement management system (PMS) should tackle all aspects of the pavement management process from planning and programming through a project's development and implementation (Shahin, 2005). A Geospatial Information System (GIS) can be used to expand and enhance each of these PMS components. A GIS can be designed as a platform on which the PMS can be built and operated. Such a system is designated as PMS/GIS (Ahmed Elhadi, 2009). In designing advanced pavement methods, the quality assurance is the practice of sampling, testing, and inspecting a product on behalf of its ultimate owner to ensure its acceptability under specifications agreed upon by contract. Quality control is the ongoing sampling and testing of a product during manufacturing for the purpose of controlling the process and detecting deficient material (James et al., 2002). In addition to providing hard surfaces for parking and driving, pavements serve as storm water storage and infiltration systems. Site planners and public works officials have found that they provide the opportunity of managing storm water storage in an environmentally friendly way as they promote infiltration, improve water quality, recharge groundwater, and keep the flow of runoff in line with non-developed areas. They have been used successfully in a variety of climates for parking lots and city streets. Recently advanced methods of asphalt reclamation, including porous pavements, have made it possible to modify the design of new systems so that they may be used more widely and at a lower cost (Hansen, 2008, West et al., 2001).

Analyses of field work by a regression method, which is based on the results of Reclaimed Asphalt Pavement (RAP), deal with the multiple variables in regression analyses to predict the benefit of RAP (Kowalski et al., 2008, Abramowitz, 1970).

In a regression method, curve estimation is most appropriate when the relationship between the dependent variable(s) and the independent variable is not necessarily linear. Linear regression is used to model the value of a dependent scale variable based on its linear relationship to one or more predictors. Nonlinear regression is appropriate when the relationship between the dependent and independent variables is 
not intrinsically linear. Binary logistic regression is most useful in modeling the probability of an event for a categorical response variable with two outcomes. The auto regression procedure is an extension of ordinary least-squares regression analysis specifically designed for time series. One of the cases underlying ordinary least-squares regression is the absence of autocorrelation in the model residuals. Time series, however, often exhibit first-order autocorrelation of the residuals. In the presence of auto correlated residuals, the linear regression procedure gives inaccurate estimates of how much of the variability of a series is accounted for by the chosen predictors.

The development of a road network in the 21 th century requires intensive research in the field of road maintenance. It is essential to develop efficient and effective methods of assessing road pavement conditions. Monitoring the level of the traffic safetyrelated characteristics (the friction coefficient and texture depth) is particularly important for road users, while keeping road noise as low as possible because of urban populations living near the traffic (Gardziejczyk, 2002, Li, et al., 2003). There are several mathematical models that calculate the performance of pavements in view of road maintenance. When using RAP in surface mixtures, friction resistance is a serious problem. The friction phenomena increase when using aggregates in RAP. The mixture and stiffness of RAP is an important factor due to making it more susceptible to cracking. The mixture of RAP is influenced by the fact that RAP is typically removed from old roadways. It may contain different types of aggregates, binders, patches, chip seals, etc. (Nady, 1997).

The U.S. National Asphalt Pavement Association provides information on the storage of RAP and identification of laboratory techniques. The friction phenomenon of a pavement is a function of the surface formation. It includes the aggregate shapes as well as the aggregate sizes and gradations. The combination of low friction aggregates with high frictional characteristics produces a blend with pavement frictional resistance. The International Friction Index (IFI) offers friction values that can be related to other parameters, such as mixes containing RAP (Lanham, 2007, Newcomb et al., 2007, McDaniel, 2003).

Stone matrix asphalt (SMA) is a gap-graded HMA that is designed to maximize deformation (rutting) resistance and durability by using a structural basis of stone-on-stone contact. Because the aggregates are all in contact, rut resistance relies on aggregate properties rather than asphalt binder properties. Since aggregates do not deform as much as asphalt binder under a load, this stone-on-stone contact greatly reduces rutting. SMA is generally more expensive than a typical dense-graded HMA (about $20-25$ percent) because it requires more durable aggregates, higher asphalt content and, typically, a modified asphalt binder and fibers. In the right situations it should be cost-effective because of its increased rut resistance and improved durability. SMA, originally developed in Europe to resist rutting and studded tire wear, has been used in the U.S. since about 1990 (NAPA, 1999).

\section{MATERIALS AND METHODS}

This paper aims to inform practitioners about the state of the practice for RAP. This is a practical way for increasing the use of RAP in asphalt pavement mixtures while maintaining high-quality pavements based on infrastructure data. This work also should be of interest to engineers, contractors, and others involved in the specification and design of asphalt mixtures for flexible pavements, as well as those involved in promoting the optimal use of RAP. The results of this work aim at raising the question of improved modeling based on the classification of measurements and a comparison with a special type of RAP versus other kinds of RAP. The location of the work was in the city of Rasht in northern Iran. The dateline for the data collection was from 09:00 a.m., 10/02/2017, until 20/07/2017.

The research process for this work can be divided into the following steps:

(1) Collecting and extracting the RAP samples were based on the GIS from 23 different locations across the pilot project.

(2) Using historical data from and guidance by the Laboratory of Soil Mechanics office in the city of Rasht.

(3) Conducting a regression analysis through the data collection procedure for the number of wheel passes and daily temperature as independent variables versus the Mean Profile Depth (MPD) as a dependent variable.

In this work the following considerations were taken into account using data for the number of wheel passes and daily temperature as independent variables versus the Mean Profile Depth (MPD) as a dependent variable (1):

$$
Y=f\left(X_{1}, X_{2}\right)
$$

The MPD with the nomenclature "Y" as a dependent variable and the number of wheel passes and daily temperature of the pilot project have the nomenclature " $\mathrm{X}$ " as the independent variables. The curve estimation procedure was used based on the MPD data which were detected by field tests. These data were compared with the number of wheel passes for the specimens. They were detected in actual conditions (field tests). Then the model was calibrated using one set of the data. Then the regression model was built based on the field test data. A scatter diagram, correlation and autocorrelation procedure for the MPD was formed by estimating the regression statistics and producing related plots for the preferred model. In this work the conclusions were drawn on the basis of experiments and calculations for the independent variables such as the number of wheel passes based on the three cases (2-4):

The first assumption includes the MPD versus the number of wheel passes and the daily temperature. The field test data (news, weather) is shown in (Tabs. 1-2).

The curve estimation procedure (Tab. 3) allows for the quick estimation of the regression statistics and the production of related plots for different models (5-13). The nomenclatures for the three cases are the following:

(1) First case (Fig. 1):

$$
t=f(n)
$$

" $t$ " is the Mean profile depth (MPD), mm,

" $n$ " is the No. of wheel passes for the specimens.

(2) Second case (Fig. 2):

$$
t=f(T)
$$

" $t$ " is the Mean profile depth (MPD), mm,

" $T$ " is the daily temperature of the pilot project as field data.

The most important effects based on the regression and summary of the model concentrated on the daily temperature of the pilot project.

(3) Third case (Fig. 1):

$$
t=f(n, T)
$$

" $t$ " : Mean profile depth (MPD), mm,

" $n$ ": No. of wheel passes for the specimens.

" $T$ " : Daily temperature of the pilot project as field data. 
Tab. 1 Field test data (news, weather)

\begin{tabular}{|c|c|c|c|c|c|}
\hline No. & Day & Temperature $\left({ }^{\circ} \mathbf{F}\right)$ Min-Max & Weather & Precipitation & Humidity (\%) \\
\hline 1 & Tuesday & $34-39$ & Mostly Cloudy & $25 \%$ & 89 \\
\hline 2 & Wednesday & $29-36$ & Light Snow Showers & $40 \%$ & 89 \\
\hline 3 & Friday & $23-42$ & Partly Cloudy & $20 \%$ & 89 \\
\hline 4 & Saturday & $22-43$ & Sunny & $0 \%$ & 89 \\
\hline 5 & Sunday & $36-51$ & Partly Cloudy & $0 \%$ & 89 \\
\hline 6 & Monday & $36-51$ & Sunny & $0 \%$ & 89 \\
\hline 7 & Tuesday & $37-58$ & Sunny & $0 \%$ & 89 \\
\hline 8 & Tuesday & $47-64$ & Partly Cloudy & $10 \%$ & 89 \\
\hline 9 & Wednesday & $45-59$ & Mostly Cloudy & $20 \%$ & 89 \\
\hline 10 & Thursday & $42-44$ & Cloudy & & 89 \\
\hline
\end{tabular}

Tab. 2 Field tests and regression stiffness model for the asphalt pavement

\begin{tabular}{|c|c|c|c|}
\hline No. & Mean Profile Depth $(\mathbf{m m})^{*}$ & No. of wheels passing** & Daily Temperature $\left({ }^{\circ} \mathbf{C}\right)$ \\
\hline 1 & 111 & 165 & 13.45 \\
\hline 2 & 120 & 159 & 13.66 \\
\hline 3 & 114 & 168 & 13.03 \\
\hline 4 & 100 & 158 & 14.30 \\
\hline 5 & 118 & 164 & 14.73 \\
\hline 6 & 109 & 166 & 17.10 \\
\hline 7 & 126 & 161 & 17.55 \\
\hline 8 & 142 & 161 & 16.28 \\
\hline 9 & 120 & 159 & 16.03 \\
\hline 10 & 134 & 167 & \\
\hline
\end{tabular}

* MPD (dependent variable, the $P$ value is equal to 0.9992)

** No. of wheels passing (independent variable, the $\mathrm{P}$ value is equal to 0.9909)

Tab. 3 Curve fit modeling for the Mean Profile Depth (mm); Daily Temperature $\left({ }^{\circ} \mathrm{C}\right)$

\begin{tabular}{|c|c|c|c|c|c|c|c|c|}
\hline \multirow{2}{*}{ Equation } & \multicolumn{5}{|c|}{ Parameter Estimates } & \multirow[b]{2}{*}{$a_{1}$} & \multirow[b]{2}{*}{$a_{2}$} & \multirow[b]{2}{*}{$a_{3}$} \\
\hline & R Square & $\mathrm{F}$ & df1 & Sig. & $a_{0}$ & & & \\
\hline $\begin{array}{c}\text { Linear (5) } \\
\mathrm{A}=20.6388-6.5060 x\end{array}$ & .619 & 13.02 & 8 & .007 & 20.6388 & 6.5060 & & \\
\hline $\begin{array}{c}\text { Logarithmic (6) } \\
\log y=\log (-149.42)+(98.9859) \log x\end{array}$ & .609 & 12.48 & 8 & .008 & -149.42 & 98.9859 & & \\
\hline $\begin{array}{l}\text { Inverse (7) } \\
\mathrm{y}=f^{-1}(y)\end{array}$ & .598 & 11.91 & 8 & .009 & 218.755 & 1495.6 & & \\
\hline $\begin{array}{c}\text { Quadratic (8) } \\
\mathrm{y}=12.9421 \mathrm{x}^{.8165}\end{array}$ & .647 & 6.43 & 7 & .026 & 320.675 & -32.751 & 1.2731 & \\
\hline $\begin{array}{c}\text { Cubic (9) } \\
\mathrm{y}=320.675+0 \mathrm{x}-32.751 \mathrm{x}^{2}-1.2731 \mathrm{x}^{3}\end{array}$ & .648 & 6.44 & 7 & .026 & 153.752 & & -.8592 & .0461 \\
\hline $\begin{array}{c}\text { Compound (10) } \\
\mathrm{A}=52.6717 \mathrm{e}^{\mathrm{t}}+1.0551\end{array}$ & .610 & 12.49 & 8 & .008 & 52.6717 & 1.0551 & & \\
\hline $\begin{array}{c}\text { Power,(11) } \\
\mathrm{y}=12.9421 \mathrm{x}^{.8165}\end{array}$ & .601 & 12.05 & 8 & .008 & 12.9421 & .8165 & & \\
\hline $\begin{array}{c}\mathrm{S}(12) \\
\left.\mathrm{y}=f_{0} \mathrm{~T}, \mathrm{X}, \mathrm{U}\right)\end{array}$ & .591 & 11.57 & 8 & .009 & 5.5982 & -12.349 & & \\
\hline $\begin{array}{c}\text { Growth (13) } \\
(\mathrm{dA} / \mathrm{dT})=3.9641 \mathrm{~A}+.0536\end{array}$ & .610 & 12.49 & 8 & .008 & 3.9641 & .0536 & & \\
\hline $\begin{array}{c}\text { Exponential }(14) \\
\mathrm{y}=(52.6717 \mathrm{E}-.0536)^{\mathrm{x}}+\end{array}$ & .610 & 12.49 & 8 & .008 & 52.6717 & .0536 & & \\
\hline $\begin{array}{c}\text { Logistic (15) } \\
\mathrm{y}=.0190 \mathrm{x}+.9478\end{array}$ & .610 & 12.49 & 8 & .008 & .0190 & .9478 & & \\
\hline
\end{tabular}

$\mathrm{t}$ - Mean profile depth $(\mathrm{mm})$ as a dependent variable; T-temperature $\left({ }^{\circ} \mathbf{C}\right)$ as an independent variable 
The dependent and independent variables for these three cases are shown in (Tabs. 1-7). The work circumstances includes the MPD data as a function of the number of wheel passes and the temperature belonging to 10 specimens, which were selected from a set of 23 specimens. The p-value is a number between 0 and 1 . In the most realistic situations, the p-value is not equal to the boundary value (especially equal to 0 ). Although it is impossible, the p-value will be equal to 1 (Tabs. 1-2).

\section{RESULTS AND DISCUSSION}

In the presented work, an auto-regression procedure was applied for the curve estimation procedure. The function curve was overlapped with a regression analysis. In the final procedure, the regression model was determined. The related plots (Figs.1-8) were produced based on the GIS for the pilot project. The curve estimation procedure (5-15) allowed for the quick estimation of the regression statistics and the production of the related plots for the defined model as shown in (Tabs. 1-7). The power function had a suitable correlation on the scatter diagram (Tab. 3).

The adjusted R-squared compares the descriptive power of the regression models with two or more variables. It includes a diverse number of independent variables known as a predictor. Therefore, a model that includes several predictors will return higher R2 values and may seem to be a better fit (Tab. 4).

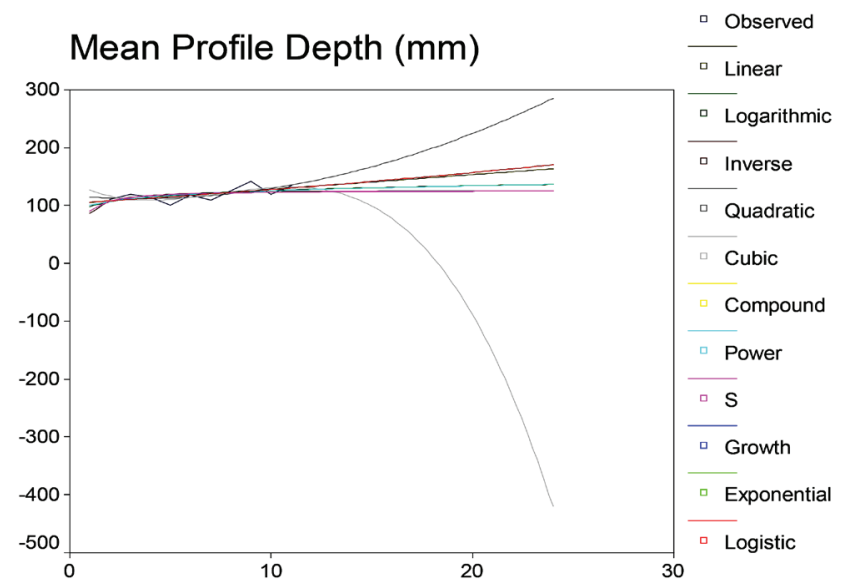

no. of wheel passing

Fig. 1 Curve Fit for Mean Profile Depth (mm); No. of wheels passing

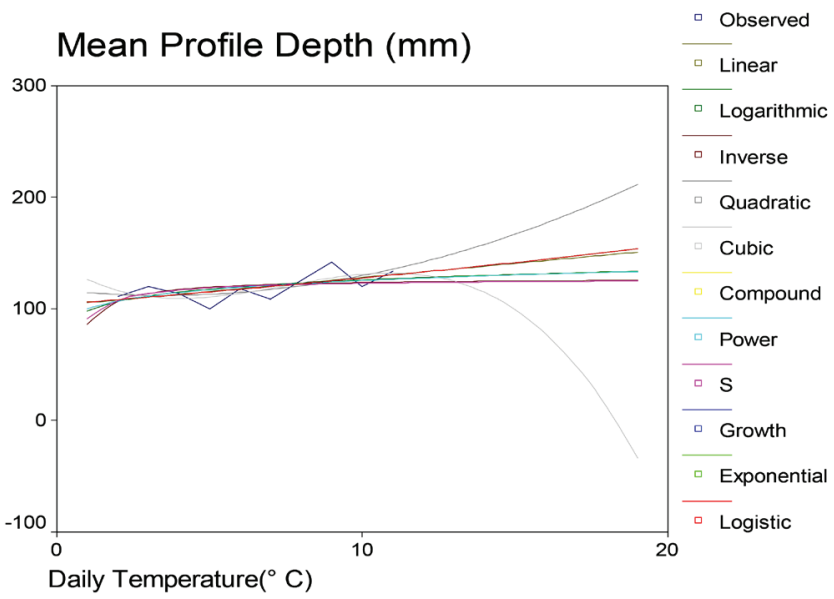

Fig. 2 Curve Fit for Mean Profile Depth (mm); Daily Temperature $\left({ }^{\circ} \mathrm{C}\right)$
Tab. 4 Model Summary for Mean Profile Depth (mm); Daily Temperature $\left({ }^{\circ} \mathrm{C}\right)$

\begin{tabular}{|c|c|c|}
\hline Multiple R & R Square & Adjusted R Square \\
\hline .957 & .915 & .891 \\
\hline
\end{tabular}

Dependent Variable: Mean Profile Depth $(\mathrm{mm})$ Predictors: Daily Temperature $\left({ }^{\circ} \mathrm{C}\right)$

Analysis of Variance (ANOVA) is a statistical method used to test the differences between two or more means. It may seem odd that the technique is called "Analysis of Variance" rather than "Analysis of Means". The name is appropriate because inferences about means are made by analyzing variances (Tab. 5).

Tab. 5 Analysis of Variance for Mean Profile Depth ( $\mathrm{mm}$ ) and Daily Temperature $\left({ }^{\circ} \mathrm{C}\right)$

\begin{tabular}{|c|c|c|c|c|c|}
\hline & $\begin{array}{c}\text { Sum of } \\
\text { Squares }\end{array}$ & df & $\begin{array}{c}\text { Mean } \\
\text { Square }\end{array}$ & F & Sig. \\
\hline Regression & 9.152 & 2 & 4.576 & 37.765 & .000 \\
\hline Residual & .848 & 7 & .121 & & \\
\hline Total & 10.000 & 9 & & & \\
\hline
\end{tabular}

Dependent Variable: Mean Profile Depth $(\mathrm{mm})$ Predictors: Daily Temperature $\left({ }^{\circ} \mathrm{C}\right)$

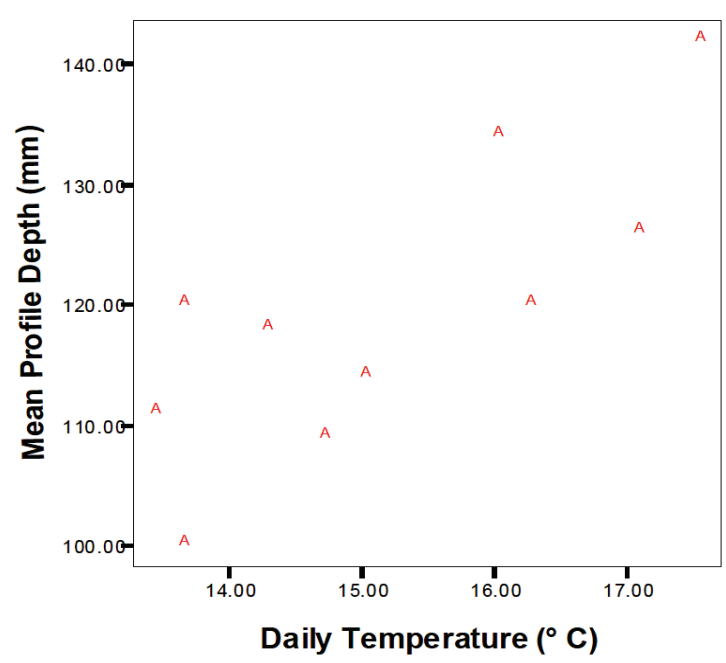

Fig. 3 2-D Scatter Mean Profile Depth (mm); Daily Temperature $\left({ }^{\circ} \mathrm{C}\right)$

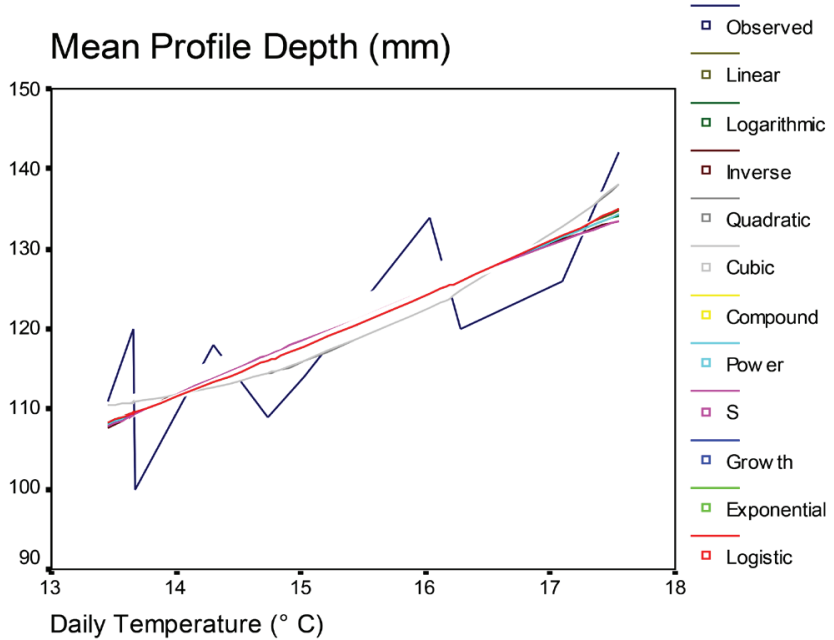

Fig. 4 Curve Fit for Mean Profile Depth (mm); Daily Temperature $\left({ }^{\circ} \mathrm{C}\right)$. 
A standardized beta coefficient compares the strength of the effect of each individual independent variable to the dependent variable. The higher the absolute value of the beta coefficient, the stronger the effect (Tab. 6).

Tab. 6 Standardized Coefficients for Daily Temperature

\begin{tabular}{|c|c|c|c|c|c|}
\hline & \multicolumn{2}{|c|}{$\begin{array}{c}\text { Standardized } \\
\text { Coefficients }\end{array}$} & df & F & Sig. \\
\cline { 2 - 3 } & Beta & Std. Error & & & \\
\hline $\begin{array}{c}\text { Daily Temperature } \\
\left({ }^{\circ} \mathrm{C}\right)\end{array}$ & .957 & .110 & 2 & 75.531 & .000 \\
\hline
\end{tabular}

Dependent Variable: Mean Profile Depth (mm)

If the correlation $>0.8$, then severe multicollinearity may be present. It is possible for individual regression coefficients to be insignificant but for the overall fit of the equation to be high. A Variance Inflation Factor (VIF) measures the extent to which the multicollinearity has increased the variance of an estimated coefficient. It can assess multicollinearity by examining tolerance, and the VIF are two collinearity diagnostic factors that can help to identify multicollinearity. Tolerance is a measure of the collinearity reported by most statistical programs such as SPSS; the variable's tolerance is 1-R2.

As a measure of collinearity, "tolerance" is used in regression analysis. These reported tolerance levels are sometimes called the tolerance statistics. The tolerance is associated with each independent variable and ranges from 0 to 1 (Tab. 7).

The functions resulted due to the curve fitting at the modeling process (5-12). The power function had a suitable correlation on the scatter diagram.

In this work, the p-values for the three variables (MPD; daily temperature; no. of wheel passes) are as the following (Tab. 8):

(1) P Value for MPD:

Chi $2=0.8, \mathrm{DF}=8$

The $\mathrm{P}$ value equals 0.9992 .

According to the conventional criteria, this difference is not considered to be statistically significant.

(2) P Value for Daily Temperature:

Chi $2=0$, DF $=9$

The $P$ value equals 0.9692 .

According to the conventional criteria, this difference is not considered to be statistically significant.

(3) P Value for no. of wheel passes:

Chi $2=1.2$, DF $=7$

The two-tailed $\mathrm{P}$ value equals 0.9909 .

The p-value is the level of marginal significance within a statistical hypothesis test that represents the probability of the occurrence of a given event. The $\mathrm{p}$-value is used as an alternative to rejection points to provide the smallest level of significance at which the null hypothesis would be rejected.
(1) Determine the experiment's expected results.

(2) Determine the experiment's observed results.

(3) Determine the experiment's degrees of freedom.

(4) Compare the expected results to the observed results with a chi square.

(5) Choose a level of significance.

(6) Use a chi square distribution table to approximate the p-value.

(7) Approximate the $p$ value for the experiment. It can be decided whether or not to reject the null hypothesis of the experiment. It can be shown that the manipulated experimental results would be highly unlikely to occur if there was no real connection between the variables that can be manipulated and the effect was observed. If the $p$ value is higher than the significance value, that claim cannot confidently be made (Tab. 8).

Tab. 8 p-value calculations

\begin{tabular}{|c|c|c|c|}
\hline & $\begin{array}{c}\text { Depth } \\
(\mathrm{mm})\end{array}$ & $\begin{array}{c}\text { Daily Temperature } \\
\left({ }^{\circ} \mathrm{C}\right)\end{array}$ & $\begin{array}{c}\text { no. of wheel } \\
\text { passing }\end{array}$ \\
\hline Chi-Square(a,b,c) & .800 & .000 & 1.200 \\
\hline $\mathrm{df}$ & 8 & 9 & 7 \\
\hline Asymp. Sig. (d) & .999 & 0.9692 & .991 \\
\hline
\end{tabular}

(a) 9 cells $(100.0 \%)$ have expected frequencies of less than 5 . The minimum expected cell frequency is 1.1 .

(b) 10 cells $(100.0 \%)$ have expected frequencies of less than 5 . The minimum expected cell frequency is 1.0.

(c) 8 cells $(100.0 \%)$ have expected frequencies of less than 5 . The minimum expected cell frequency is 1.3 .

(d) The Sig (2-tailed) item in the output is the two-tailed p-value. The $\mathrm{p}$-value is the evidence against a null hypothesis. If there is a small $\mathrm{p}$-value in this area, then the test has a significant result.

\subsection{Climate table/historical weather data of Rasht (https://www.yahoo.com/news/weather)}

At an average temperature of $24.7{ }^{\circ} \mathrm{C}$, August is the hottest month of the year. The lowest average temperatures in the year occur in February, when it is around $7.1^{\circ} \mathrm{C}$. Between the driest and wettest months, the difference in precipitation is $195 \mathrm{~mm}$. The variation in temperatures throughout the year is $17.6{ }^{\circ} \mathrm{C}$. When reading the climate table, for every month, you will find data about precipitation $(\mathrm{mm})$ and the average, maximum and minimum temperatures (degrees Celsius and Fahrenheit). The meaning of the first line is: 1/ January, 2/ February, 3/ March, 4/ April, 5/ May, 6/ June, 7/ July, 8/ August, 9/ September, 10/ October, 11/ November, 12/ December (Fig. 6-7).

Tab. 7 Correlations and Tolerance.

\begin{tabular}{|c|c|c|c|c|c|c|}
\hline & \multicolumn{3}{|c|}{ Correlations } & \multirow{2}{*}{ Tolerance } \\
\cline { 2 - 4 } & Zero-Order & Partial & Part & Importance & $\begin{array}{c}\text { After } \\
\text { Transformation }\end{array}$ & $\begin{array}{c}\text { Before } \\
\text { Transformation }\end{array}$ \\
\hline Daily Temperature $\left({ }^{\circ} \mathrm{C}\right)$ & .957 & .957 & .957 & 1.000 & 1.000 & 1.000 \\
\hline
\end{tabular}

Dependent Variable: Mean Profile Depth (mm) 


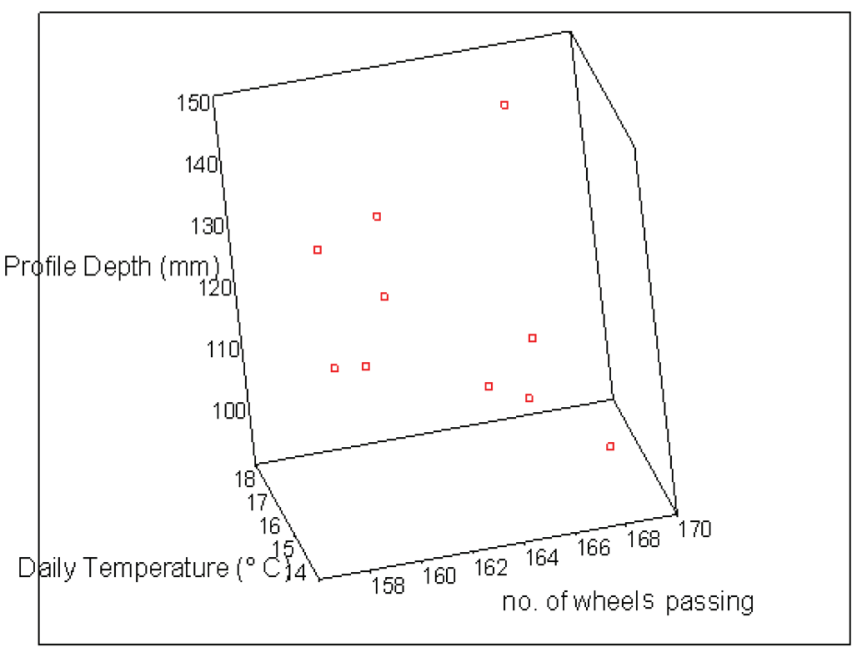

Fig. 5 3-D Scatter of: Mean Profile Depth (mm); no. of wheels passing; Daily Temperature $\left({ }^{\circ} \mathrm{C}\right)$

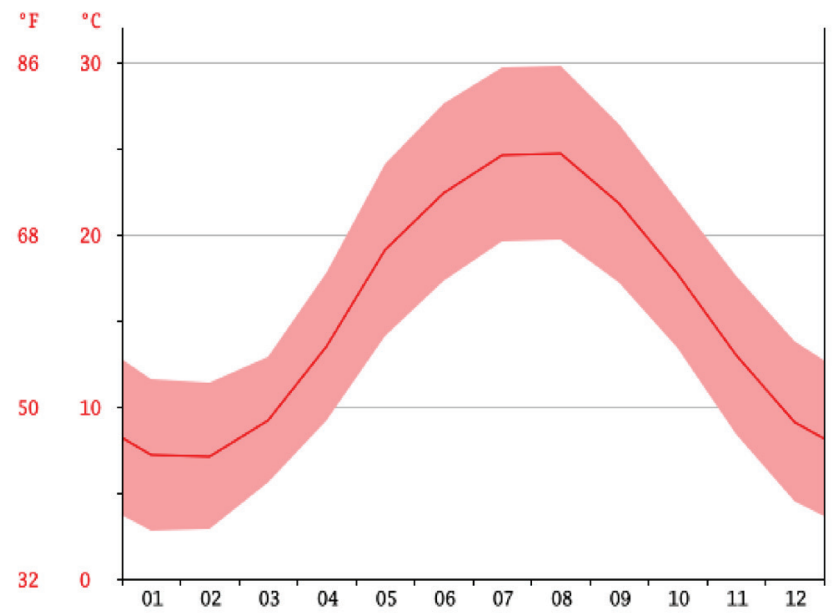

Fig. 6 Historical climate data of the city of Rasht

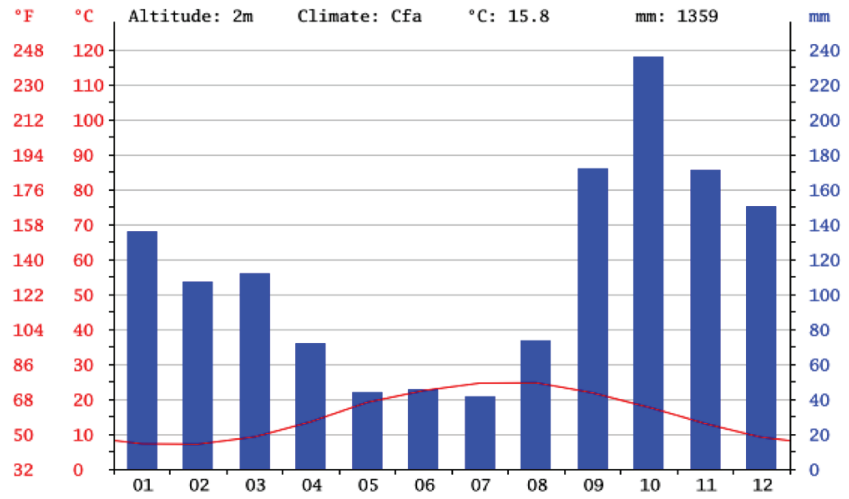

Fig. 7 Climate table with the weather data of the city of Rasht

\subsection{Comparison with other works}

The results of the present work (Fig. 8) were compared with the works of other experts. Kowalski, McDaniel and Olek (Kowalski et al., 2008) obtained the aggregate type and mixture proportions of RAP. The comparison showed a similarity with the present work and the results of their work.

\section{CONCLUSIONS}

This work presented an experimental examination of the performance of statistical modeling based on a data comparison with a special type of pavement called RAP versus other types of RAP.

(1) Mathematical regression models were developed for the firstorder auto correlated residuals. It ease put the provided a reliable estimate of both the goodness-of-fit measures and the significance levels of the predictor variables chosen. The power function had a suitable correlation on the scatter diagram.

(2) The present work compares the pavement data for the number of wheel passes and temperature versus the MPD. The results include the MPD data as a function of the number of wheel passes and the temperature for the Stone Matrix Asphalt (SMA) of the 10 specimens.

(3) The results showed a good correlation between the parameters: the P Value Results for Depth (mm) equals 0.9992, the P Value Results for the Daily Temperature $\left({ }^{\circ} \mathrm{C}\right)$ equals 0.9692 , and the $\mathrm{P}$ Value Results for the number of wheel passes equals 0.9909 .

(4) The results of this work will help to reduce energy expenditures due to optimizing the cost and stiffness of an asphalt pavement.

\section{Acknowledgment}

This work was a part of the MSc thesis of Hossein Hariri Asli (corresponding author), under contract no: 20652301069 date: 23/11/2015, with the Civil Engineering Department, Faculty of Engineering, University of Guilan, Iran.

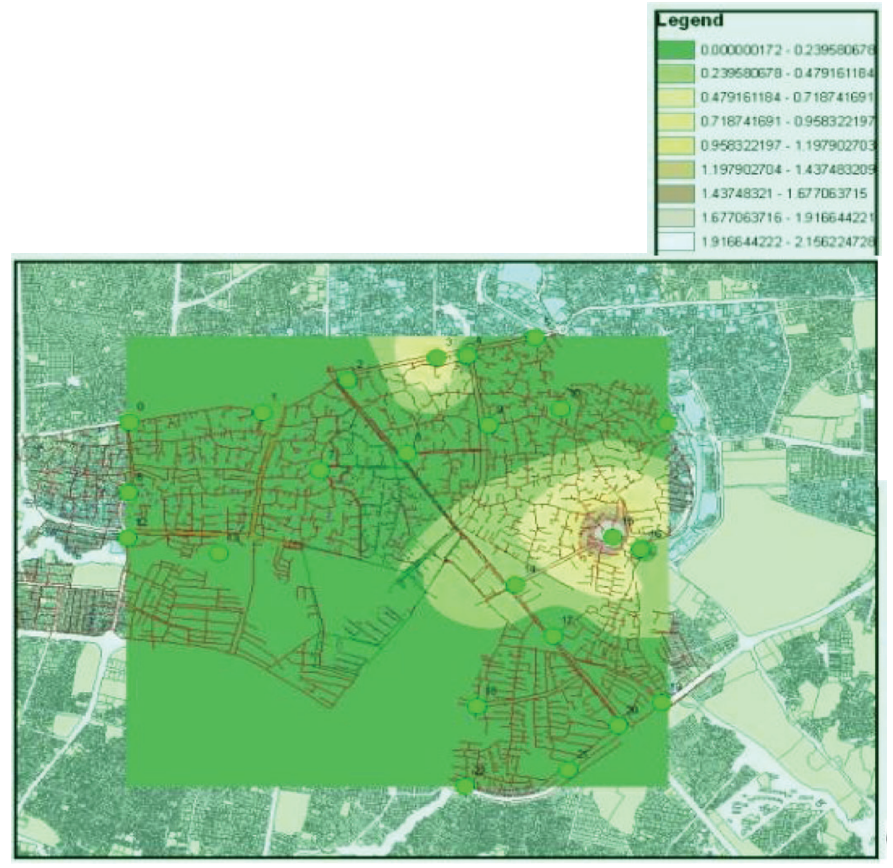

Fig. 8 RAP samples from 23 different locations: based on the Geospatial Information System (GIS), city of Rasht 


\section{REFERENCES}

Abramowitz, M.- Stegun, I.A. (1970) Handbook of Math Functions, Washington D.C.

Ahmed Elhadi, H. M. (2009) GIS, a tool for pavement management, Department of Urban Planning and Environment School of Architecture and the Built Environment, Royal Institute of Technology (KTH) 10044 Stockholm, Sweden TRITA-GIT EX 09-02.

Climate table. (2117) Historical weather data of Rasht. Available at: https://www.yahoo.com/news/weather

Gardziejczyk, W. (2002) Texture of Road Surfaces, Methods of Measurement Parameters Evaluation and Its Influence on the Tire/Road Noise. Drogi Mosty, No. 2, Poland, 5-29.

Hansen, K. (2008) Porous Asphalt Pavements for Storm Water Management. Design, Construction and Maintenance Guide, Information Series 131, 27.

James, R. - Eason, P. E. - James F.- Shook, P. E. (2002) National Asphalt Pavement Association, Information Series 109, Lanham, Maryland, USA, 68.

Kowalski, K. J. - McDaniel, R. S. - Olek, J.- Shah, A. - Li, S. (2008) Development of the International Friction Index Flag Value. 10th International Conference on Application of Advanced Technologies in Transportation, Athens, Greece, Paper No. 705.

Kowalski, K. J. - McDaniel, R. S. - Olek, J. (2008) Development of a Laboratory Procedure to Evaluate the Influence of Aggregate Type and Mixture Proportions on the Frictional Characteristics of Flexible Pavements. Journal of the Association of Asphalt Paving Technologists, Vol. 77, 35-70.

Li, S., Noureldin - S. - Zhu, K. (2003) Upgrading the INDOT Pavement Friction Testing Program. Final Report FHWA/IN/JTRP2003/23, West Lafayette, Indiana, USA.
Lanham, M. D. (2007) A Practical Guide, Quality Improvement Series, 124. National Asphalt Pavement Association, March 2007, 36 .

McDaniel, R. S. - Coree, B. J. (2003) Identification of Laboratory Techniques to Optimize Super Pave HMA Surface Friction Characterization. Phase I: Draft Final Report. Institute for Safe, Quiet and Durable Highways, SQDH 2003-6, West Lafayette, Indiana, USA.

Nady, R. M. (1997) The Quality of Random RAP; Separating Fact from Supposition. National Asphalt Pavement Association, HMAT magazine, Lanham, MD, vol. 2, No. 2, 14-17.

National Asphalt Pavement Association (NAPA) (1999) Designing and Constructing SMA Mixtures - State-of-the-Practice, Quality Improvement Series 122. National Asphalt Pavement Association. Lanham, MD.

Newcomb, D. E.- Brown, E. R. - Epps, J. A. (2007) Quality Improvement Series, 124, Designing HMA Mixtures with High RAP.

Shahin, M.Y. (2005) "Pavement Management for Airports, Roads, and Parking Lots", 2d ed., Washington D.C.

West, T. R.- Choi, J. C. - Bruner, D. W. - Park, H. J. - Cho, K. H. (2001) Evaluation of Dolomite and Related Aggregates Used in Bituminous Overlays for Indiana Pavements. Transportation Research Record, vol. 1757, 137-147.
Nomenclatures
$t$ : MPD, mm,
$n$ : No. of wheel passes for specimens.
$T$ : Daily temperature of pilot project as a field data.
$Y$ : Nomenclature of dependent variable
$X$ : Nomenclature of independent variable 